\title{
Application of Polyphenol Extract from Mango Peel Powder as a Source of Natural Phytonutrients into Biscuits
}

\author{
Baddi Jayalaxmi $^{1 *}$, D. Vijayalakshmi ${ }^{1}$ and A. Maruthesha ${ }^{2}$ \\ ${ }^{1}$ Department of Food Science and Nutrition, UAS, GKVK, Bengaluru, Karnataka, India \\ ${ }^{2}$ Department of Food Science, Agricultural and Horticultural Research Station, \\ Kathalagere, UHS, Shivamogga, Karnataka India \\ *Corresponding author
}

\begin{tabular}{|c|}
\hline Keywords \\
\hline $\begin{array}{l}\text { Mango peel powder, } \\
\text { Total polyphenols, } \\
\text { Biscuits and retention of } \\
\text { polyphenols extract }\end{array}$ \\
\hline Article Info \\
\hline $\begin{array}{l}\text { Accepted: } \\
10 \text { April } 2018 \\
\text { Available Online: } \\
10 \text { May } 2018\end{array}$ \\
\hline
\end{tabular}

\section{Introduction}

Mango (Mangifera indica L., Anacardiaceae) is truly a "King" of fruits has been cultivated for about 4,000 years and its production and consumption has gradually increased as its popularity has grown. During processing of mango, by-products such as peel and kernel constitutes about 17-22 per cent of the fruit (Pitchaon 2011). In India the area under cultivation occupies 2312.3 hectares with production of 15,026.7 MT of mangoes, which ranks second among the major fruits and in Karnataka the area is 153.8 hectares with production of $1694 \mathrm{MT}$, as reported by National Horticulture Board (2010). Besides the fresh fruit, processed mango products such as juices, nectars, concentrates, jams, jelly, powders, fruit bars, flakes and dried fruits have become increasingly popular. Since these byproducts represent a serious disposal problem, ways for a sustainable agricultural production has been searched (Kimberly and Krenek, 2009).

The characteristic feature of mango peel is that it has relatively high content of polyphenols and dietary fibre, which is 
reported to have more health benefits compared to apple peel, orange peel, wheat bran and oat bran. The bioactive components namely, carotenoids, flavanols, and polyphenols, which exert higher health promoting effects than the dietary fibre alone. As peel is not currently being utilized for any commercial purpose, it is discarded and becoming a source of pollution. Recently Ajila et al., (2007) reported that mango peel contains polyphenols and dietary fibers which need to exploited as natural phyto- nutrients. The objective of present study was to process the mango peel and analyze the nutrient composition, extraction of total polyphenols from mango peel powder, development of value added biscuits and to analyze the retention of extracts in the developed products.

\section{Materials and Methods}

The Mango peel for research was procured from a local mango processing Safal, industry, Bangalore, Karnataka, India. The sample was cleaned, blanched and dried in hot air oven at $50^{\circ}$ C. The material was ground to fine powder passed through a 60 mesh sieve and stored at in air tight container in refrigerator conditions for further use. The mango peel samples were finely powdered and were subjected for chemical analysis. The nutrients analyzed were moisture, protein, fat, crude fiber, total dietary fiber (soluble and insoluble), and total polyphones and $\beta$ carotene, ash, calcium, phosphorous, iron and zinc in mango peel powder by AOAC methods. Carbohydrate and energy were computed.

Estimation of insoluble dietary fiber, soluble dietary fiber and total dietary fiber (AOAC, 1995)

Defatted foods are gelatinized and proteins and starch are removed by enzymatic digestion. The residue is quantitated gravimetrically. The soluble fiber is estimated in the filtrate obtained after enzymatic digestion of protein and carbohydrates of defatted sample. The insoluble fiber is precipitated and estimated gravimetrically. The total dietary fiber is the sum of the insoluble and soluble dietary fiber, estimated as follows;

Total Dietary Fiber $=\mathrm{IDF}+\mathrm{SDF}$ values

\section{Extraction of total polyphenols (TPP)}

Extraction of bulk quantities of total polyphenols from stabilized mango peel powder. $100 \mathrm{gm}$ of mango peel powder was extracted with $1000 \mathrm{ml}$ of $80 \%$ acetone for $4-5$ hr by stirring with magnetic stirrer. The slurry was then strained through muslin cloth to separate the extract. The total polyphenols extracts were then subjected to vacuum evaporation (Rotary evaporator) at 450C to remove acetone completely and concentrated to get total polyphenols extract in liquid form. Stored in air tight container and kept in cool place. The extraction was repeated to obtain crude total polyphenols extract and was used for product development (Sadasivam and Manickam, 1991).

\section{Estimation of total polyphenols}

0.5 to $1.0 \mathrm{gm}$ of the sample and ground with a pestle and mortar in 10 times volume of 80 percent ethanol. Centrifuged at 10000 RPM for $10 \mathrm{~min}$ collect supernatant. Re-extracted the residue with 5 times volume of 80 percent ethanol centrifuge and poor the supernatants. Evaporate the supernatants to dryness over water bath. the residue in a known volume of distilled water $(3 \mathrm{ml})$. Pipette out 0.5 and 1.0 $\mathrm{ml}$ into test tube. Add distilled water to make up the volume to $3 \mathrm{ml} .0 .5 \mathrm{ml} \mathrm{FCR}$ was added to each test tube. After $30 \mathrm{~min}, 2 \mathrm{ml}$ of 20 percent $\mathrm{NaCO}_{3}$ solution was added to each test 
tube. Mixed thoroughly and the tube was placed in boiling water bath for exactly $1 \mathrm{~min}$, cool and measure OD at $650 \mathrm{~nm}$ (Sadasivam and Manickam, 1991).

\section{Estimation of antioxidant activity by DPPH method}

The 2, 2- diphenyl (DPPH) radical was the oxidizing radical to be reduced by the antioxidant $(\mathrm{AH})$ present in the given sample. The disappearance of the DPPH radical absorption at $517 \mathrm{~nm}$ by the action antioxidants is measured spectrophotometrically in a methanol solution until the absorbance remains constant.

The antioxidant activity was expressed in terms of ascorbic acid equivalents; so ascorbic acid is taken as standard. Various concentrations of ascorbic acid were prepared and added to DPPH solution. The decrease in O.D is plotted against concentration of ascorbic acid. The concentration of sample was calculated using the standard curve. (Sadasivam and Manickam, 1991).

Development of value added biscuits with the incorporation of extracted total polyphenols (TPP)

Biscuits were developed with different levels of incorporation of total polyphenols and the best accepted product was taken for shelf life study and retention of extracts during storage period. Biscuits were prepared from dough containing $0.25,0.5,0.75,1.0$ and 1.5 per cent mango peel total polyphenol (TPP) levels for wheat flour and control biscuits without (TPP). The formula used was as follows: 100 $\mathrm{g}$ wheat flour, $25 \mathrm{~g}$ sugar, $30 \mathrm{~g}$ shortening, baking powder 0.5 per cent. The powdered sugar and fat were creamed was added to the cream. The contents were mixed to obtain a homogenized and pluffy texture. Sieved flour was added to the cream and mixed. The dough pieces were sheeted, cut using a circular mould and baked at $160^{\circ} \mathrm{C}$ for $9-10 \mathrm{~min}$. After baking, biscuits were cooled at room temperature, were wrapped tightly and kept at room temperature in storage materials viz., high density polythene food grade pouches of 350 gauge for further analysis.

\section{Effect of total polyphenols (TPP) extracts of mango peel powder on the physical properties of biscuits}

Diameter (W) of biscuits was measured by laying six biscuits edge-to-edge with the help of a scale. The same sets of biscuits were rotated at $90^{\circ}$ and the diameter was remeasured. Average values were reported in millimeter. Thickness (T) of biscuits was measured by stacking six biscuits on top of one another and taking the average in millimeter. The spread ratio was calculated by dividing diameter $(\mathrm{W})$ by thickness $(\mathrm{T})$.

\section{Sensory evaluation of developed products}

Criteria for selection of the panel members was their familiarity with the developed products selected for value addition. The panel members were exposed to all the products as preliminary evaluation before the final evaluation. Organoleptic evaluation of value added products: The value added biscuits were standardized in laboratory and organoleptic evaluation was carried out. A nine-point Hedonic Scale was adopted for the evaluation by semi trained panellists. Biscuits incorporated with total polyphenols (TPP) extract from mango peel powder were coded and submitted to sensory evaluation by fifteen semi-trained panel member of Department of Food Science and Nutrition. The panellists were asked to rate each sensory attribute using the control biscuits as the basic for evaluation. Biscuits were evaluated for appearance, texture, colour, aroma, taste and overall acceptability on a 9-point hedonic scale. 


\section{Statistical analysis}

Complete Randomized Design (CRD) analysis of variance was applied and the data obtained for each nutrient and functional property was subjected to statistical analysis to determine the level of significance. One-way analysis of variance was applied to sensory scores. The statistical analysis was done by using Minitab software (Minitab v1511). Significant difference was defined as $\mathrm{p} \leq 0.05$ and $\mathrm{p} \leq$ 0.01 .

\section{Results and Discussion}

The pre tested mango peel was safe from microbes, heavy-metals and pesticide residue and used for the further processing, i.e. for the extraction of total polyphenols and used for formulation of biscuits. Per cent recovery of fresh mango peel to powder form shows that there was loss of sample due to moisture. Peel contains about 80 per cent moisture. On heat at $60^{\circ} \mathrm{C}$ most of it is lost due to evaporation in each step of processing and 20 per cent recovery was obtained, which is lower as compared to the reported values by Ruiz et al., (2011) obtained 40 per cent after processing.

Per cent recovery of dietary fiber (DF) and total polyphenol (TPP) extract were obtained from the extraction protocol as presented in Table 1 . It reveals that the total dietary fiber recovery was 69.86 , insoluble dietary fiber 44.23, soluble dietary fiber 24.63 and total crude polyphenols $4.5 \mathrm{~g}$ per $100 \mathrm{~g}$ of mango peel sample. The antioxidant activity was 76.96 Vitamin C Eq.mcg/100g. These values are in concurrence with Wachiriasiri et al., (2009) who reported that the yield of $41.9 \mathrm{~g}$ per $100 \mathrm{~g}$ dry weight of banana peel on wet milling processing method. Palmeira et al., (2012) reported that a maximum extraction yield of 33.7 per cent of phenolics was obtained for the espada variety with ethanol concentration. The total dietary fiber, insoluble dietary fiber and soluble dietary fiber in the present study was $69.86,44.23$ and $24.63 \mathrm{~g} / 100 \mathrm{~g}$ of MPP; $\beta$-carotene $5600 \mu \mathrm{g} / \mathrm{g}$; total polyphenols $4.5 \mathrm{mg} \mathrm{GAE} / 100 \mathrm{~g}$ and antioxidant activity 76.96 per cent. Which were on par of values reported by Ajila et al., (2007). Similar values were also reported by Larrauri et al., (1997) that dried mango peel contained 28.1 per cent of SDF and 43.4 per cent IDF. For health benefits, it is reported that 30 to 50 per cent SDF and 50 to 70 per cent insoluble dietary fiber are considered to be well- balanced proportions.

Biscuits are the most popularly consumed bakery items in India and other parts of the world. Some of the reasons for such wide popularity are their ready to eat nature, affordable cost, good nutritional quality, availability in different tastes and longer shelf life. Hence the product biscuits were selected for TPP extract incorporation as it will be useful as phyto- nutrients. In the present study biscuits were prepared in five variations $(0.25$, $0.5,0.75,1.0$ and 1.5. Control samples were prepared without addition of TPP extracts.

Effects of total polyphenol (TPP) extracts of mango peel powder on the physical properties of biscuits were studied. Table 2 indicates that there was no significant difference among weight of biscuits where as significant difference was observed in diameter, thickness and spread ratio. TPP at 1.5 per cent level of incorporation had highest weight of $15.2 \mathrm{~g}$ and lowest was in control biscuits (15g). The TPP with 1.5 per cent had highest diameter $69.3 \mathrm{~mm}$ and control had lowest diameter $63.5 \mathrm{~mm}$. The diameter of the biscuits increased with the levels of incorporation of TPP. Control biscuit had highest thickness $(25 \mathrm{~mm})$ and biscuit with TPP 1.5 per cent had lowest $(15.9 \mathrm{~mm})$, with increase in TPP levels there was decrease in thickness of biscuits and the spread ratio was highest for biscuit with TPP 1.5 per cent $(4.3 \mathrm{~mm})$. 
Table.1 Per cent recovery of total dietary fibre, total polyphenols extract and antioxidant activity of MPP

\begin{tabular}{|l|r|}
\hline Components & Contents \\
\hline Total dietary fiber (TDF) \% & 69.86 \\
\hline Insoluble dietary fiber (IDF) \% & 44.23 \\
\hline Soluble dietary fiber (SDF) \% & 24.63 \\
\hline IDF/SDF ratio & 1.80 \\
\hline Total Polyphenols (g GAE/100g) & 4.50 \\
\hline Antioxidant activity (Vit-C Eq. $\mu \mathrm{g} / \mathrm{g}$ ) & 76.96 \\
\hline
\end{tabular}

Table.2 Physical properties of biscuits

\begin{tabular}{|l|c|c|c|c|}
\hline $\begin{array}{l}\text { Level of incorporation } \\
\text { (per cent) }\end{array}$ & $\begin{array}{c}\text { Weight } \\
(\mathbf{g})\end{array}$ & $\begin{array}{c}\text { Diameter } \\
(\mathbf{m m}) \mathbf{W}\end{array}$ & $\begin{array}{c}\text { Thickness } \\
(\mathbf{m m}) \mathbf{~ T}\end{array}$ & Spread ratio (W/T) \\
\hline Control & 15.0 & 63.5 & 25.0 & 2.5 \\
\hline TPP 0.25 & 15.0 & 64.4 & 23.1 & 2.9 \\
\hline TPP 0.5 & 15.1 & 65.4 & 20.2 & 3.2 \\
\hline TPP 0.75 & 15.1 & 67.4 & 17.4 & 3.8 \\
\hline TPP 1.0 & 15.1 & 69.2 & 16.3 & 4.2 \\
\hline TPP 1.5 & 15.2 & 69.3 & 15.9 & 4.3 \\
\hline F-value & NS & $* *$ & $* *$ & $* *$ \\
\hline SEm \pm & 3.33 & 20.09 & 44.0 & 1.7 \\
\hline CD at 1\% & 0.35 & 0.86 & 2.46 & 0.23 \\
\hline NS - Non-significant & & $* *$ Significant at 1\% level & \\
\hline
\end{tabular}

Table.3 Mean sensory scores of biscuits

\begin{tabular}{|l|c|c|c|c|c|c|}
\hline Per cent of TPP & Appearance & Texture & Colour & Flavour/ & Taste & $\begin{array}{c}\text { Overall } \\
\text { in Biscuit }\end{array}$ \\
\cline { 1 - 5 } & 8.80 & 8.60 & 8.71 & 8.50 & 8.50 & 8.70 \\
\hline Control & 8.50 & 8.41 & 8.51 & 8.35 & 8.41 & 8.40 \\
\hline TPP 0.25\% & 8.60 & 8.50 & 8.60 & 8.41 & 8.50 & 8.50 \\
\hline TPP 0.5\% & 8.13 & 8.32 & 7.70 & 7.61 & 7.72 & 8.02 \\
\hline TPP 0.75\% & 7.81 & 7.50 & 7.40 & 7.60 & 7.10 & 7.71 \\
\hline TPP 1.0\% & 6.20 & 6.31 & 6.60 & 6.10 & 6.50 & 6.43 \\
\hline TPP 1.5\% & $* *$ & $* *$ & $* *$ & $* *$ & $* *$ & $* *$ \\
\hline F-value & 9.48 & 7.52 & 6.77 & 8.04 & 6.51 & 1.74 \\
\hline SEm \pm & 0.19 & 0.25 & 0.24 & 0.19 & 0.22 & 0.16 \\
\hline CD at 1\% & & & & & \\
\hline
\end{tabular}

TPP- Total polyphenols

** Significant at $1 \%$ level. 
Table.4 Mean sensory scores of biscuits on storage

\begin{tabular}{|c|c|c|c|c|c|c|c|}
\hline \multirow[t]{4}{*}{ Biscuits } & \multirow[b]{2}{*}{ Duration } & \multirow{4}{*}{ Appearance } & \multirow{4}{*}{ Texture } & \multicolumn{2}{|c|}{ Sensory attributes } & \multirow{4}{*}{ Taste } & \multirow{4}{*}{$\begin{array}{l}\text { Overall } \\
\text { Acceptability }\end{array}$} \\
\hline & & & & \multirow{3}{*}{ Colour } & \multirow{3}{*}{$\begin{array}{l}\text { Flavour } \\
\text { / } \\
\text { Aroma }\end{array}$} & & \\
\hline & \multirow{2}{*}{ Weeks } & & & & & & \\
\hline & & & & & & & \\
\hline \multirow[t]{3}{*}{ Control } & Initial & 8.8 & 8.6 & 8.7 & 8.5 & 8.5 & 8.7 \\
\hline & $2^{\text {nd }}$ week & 7.5 & 7.0 & 7.8 & 7.1 & 7.0 & 7.1 \\
\hline & $4^{\text {th }}$ week & - & - & - & - & - & - \\
\hline TPP & Initial & 8.6 & 8.5 & 8.6 & 8.4 & 8.6 & 8.5 \\
\hline \multirow[t]{3}{*}{$0.5 \%$} & $2^{\text {nd }}$ week & 7.2 & 7.8 & 7.7 & 7.9 & 7.8 & 7.6 \\
\hline & $4^{\text {th }}$ week & 5.7 & 5.0 & 5.8 & 6.0 & 6.3 & 5.8 \\
\hline & $6^{\text {th }}$ week & 5.5 & 4.3 & 5.1 & 5.4 & 4.5 & 5.4 \\
\hline \multicolumn{2}{|c|}{ F-value } & $* *$ & $* *$ & $* *$ & $* *$ & $* *$ & $* *$ \\
\hline \multicolumn{2}{|c|}{ SEm \pm} & 13.84 & 19.0 & 12.19 & 10.29 & 8.63 & 12.57 \\
\hline \multicolumn{2}{|c|}{$\mathrm{CD}$ at $1 \%$} & 0.63 & 0.46 & 0.36 & 0.32 & 0.38 & 0.27 \\
\hline
\end{tabular}

** Significant at 1 per cent level

The effect of replacing $0.25,0.75,1.0$ and 1.5 of wheat flour with TPP on physical properties of biscuits was studied and the data presented in Table 2. With increase in the incorporation level of TPP there was increase in the diameter of biscuits (64.4 to $69.3 \mathrm{~mm}$ ), decrease in the thickness (23.1 to $15.9 \mathrm{~mm}$ ) and an increase in the spread ratio from 2.9 to 4.3. These observations are in agreement with the results obtained by Ajila et al., (2008) and Ashoush and Gadallah (2011).

Total polyphenol enriched biscuits were developed by incorporating $0.25,0.5,0.75$, 1.0 and 1.5 per cent level. Sensory evaluations of biscuits are presented in the Table 3. The control biscuits showed highest scores of $8.8,8.6,8.7,8.5,8.6$ and 8.7 for appearance, texture, colour, aroma, taste and overall acceptability respectively. The biscuits with TPP at 0.5 per cent were best accepted for sensory attributes among the variations. When analyzed statistically, the mean sensory scores were found to be significant at 1 per cent level. Total polyphenol enriched biscuits were developed by incorporating $0.25,0.5$, $0.75,1.0$ and 1.5 per cent level. The mean sensory scores of biscuits presented in Table 3 reveals that biscuits were accepted till the 1.5 percent incorporation TPP extract but the best accepted was 0.5 levels $\quad(8.5$ overall acceptability) which is next to the control biscuits. As the TPP incorporation increased from 0.25 to 1.5 the sensory scores decreased due to dark in colour and hard texture. These values are similar to the values reported by Ajila et al., (2008) and Asoush and Gadallah, (2011).

Biscuits (control and TPP 0.5 per cent level) were kept for storage study. The samples were observed daily for visual changes and were subjected to sensory evaluation on weekly basis. The results of the mean sensory evaluation of biscuits from initial day to end of storage study period are presented in the 
Table 4 depicts that the control biscuits showed highest scores of 8.8, 8.6, 8.7, 8.5, 8.5 and 8.7 for all the sensory parameters for the initial day, However at the end of second weeks the control biscuits had lower scores of (7.5, 7.0, 7.8, 7.1, 7.0 and 7.1) for appearance, texture, colour, aroma, taste and overall acceptability and by fourth week they were unfit for the sensory evaluation due to microbial growth. The TPP biscuits with 0.5 percent incorporation showed scores of 8.6, $8.5,8.6,8.4,8.6$ and 8.5 for appearance, texture, colour, aroma, taste and overall acceptability respectively at initial day which are on par with control values and had shelf life up to 4 weeks. However, at end of sixth week scores showed decreasing trend (5.5, 4.3, 5.1, 5.4, 4.5 and 5.4) for all the sensory parameters. Statistical analysis revealed a significant difference for all the sensory characteristics between control and TPP biscuit from initial to the end of storage period. Shelf life is a major consideration in developing, producing and marketing food product it refers to the time during which a product remains 'acceptable' to a consumer in terms of sensory characteristics. Many factors influence the shelf life of a product viz., moisture loss, and spoilage due to microorganism, enzymatic changes and oxidation (Adegoke et al., 1998).

The biscuits exhibited highest mean scores in the initial period for both control and TPP biscuits. The mean scores for appearance, texture, colour, flavor, taste and overall acceptability showed decreasing trend during second week of storage in both control and TPP biscuits. But the mean scores for TPP biscuits were higher than control which confirms that natural extraction has antioxidant property which in turn increased the shelf life of biscuits. Similar results were found by Reddy et al., (2005) who reported that biscuits treated with natural antioxidant extracted from raisins and drumstick leaves received higher sensory scores during storage period of 6 weeks, than control and butylated hydroxyl anisole biscuits.

Consumers are currently demanding less use of chemicals, so more attention had been paid to search for naturally occurring substances from plant sources. This is particularly true for plant materials that act as alternative antioxidant sources. Results of sensory evaluation reveal that the mango peel extract at concentrations of 0.5 per cent may be used in place of synthetic antioxidants, since these extracts had no effect on the organoleptic properties of the biscuit. In addition, natural antioxidants are safe and impart health benefits to the consumer.

\section{References}

Adegoke, G. O., Vijay Kumar, M., Gopal Krishna, A. G., Varadaraj, M. C., Sambaiah, K., and Lokesh, B. R. (1998). Antioxidants and lipid oxidation in foods. Journal of Food Science and Technology, 35(4), 283-298.

Ajila, C. M., Bhat, S. G. and Prasada Rao, U. J. S., 2007, Valuable components of raw and ripe peels from two Indian mango varieties. Food Chemistry, 102:1006-1011.

Ajila, C.M., Leelavathi, K and Prasada Rao, U. J. S., 2008, Improvement of dietary fiber content and antioxidant properties in soft dough biscuit with the incorporation of mango peel powder. $J$. Cereal Sci., 48: 319-326.

AOAC. 1980, Official Methods of Analysis, $13^{\text {th }}$ edition, Association of Official Analytical Chemists, Washington. DC.

AOAC. 1995, Official Methods of Analysis, $18^{\text {th }}$ edition, Association of Official Analytical Chemists, Washington, DC.

Ashoush, I. S. and Gadallah. M.G.E., 2011, Utilization of mango peels and seed kernels powders as sources of 
phytochemicals in biscuit. World Journal of Dairy \& Food Sciences., 6(1): 35-42.

Kimberly and Krenek, 2009, HPLC and mass spectroscopic characterization of mango (Mangiferaindical.) Gallotannins following enzymatic hydrolysis. M.Sc. thesis. Department of Nutrition and Food Science. Texas A\&M University.

Larrauri, J. A., Ruperez, P., and SauraCalixto, F., 1997, New approaches in the preparation of high dietary fibre from fruit by-products. Trends in Food Science and Technology, 29: 729-733.

Larrauri, J. A., Ruperez, P., Borroto, B. and Saura-Calixto, F., 1997, Mango peel as a new tropical fibre: preparation and characterization. Lebensmittel Wissenschaft Und Technology, 29:729733.

NATIONAL HORTICULTURE BOARD (2010), Ministry of Agriculture, Government of India.

Palmeira S. M. V., Gois, L. M. and Souza, L. D., 2012, Extraction of phenolic compounds from mango peels. Latin American Applied Research, 42:77-81.

Pitchaon, M., 2011, Antioxidant capacity of extracts and fractions from mango (Mangifera indica Linn.) seed kernels. International Food Research Journal., 18: 523-528.

Ruiz, C., Ramírez, C., Piñeres, C.G, Ángulo, M and Hedreira, G., 2011, Obtaining and characterization of mango peel powder and its use as a source of fiber and a functional ingredient in natural yogurt. iCEF11 International congress on engineering and food. Food process engineering in a changing world. May 22-26.

Rupasinghe, H. P. V., Wang. L, Huber, G. M. and Pitts, N. L., 2008, Effect of baking on dietary fiber and phenolics of muffins incorporated with apple skin powder. Food Chem., 107:1217-1224.

Sadasivam, S. and Manickam, A., 1991, Second edition, Biochemical methods. New age International Publishers.

Wachiriasiri, P., Julakarangka, S. and Wanlapa, S., 2009, The Effect of banana peel preparation on properties of banana peels dietary fiber concentrate. Songklanakarin J. Sci. Technol., 31(6): 605-611.

\section{How to cite this article:}

Baddi Jayalaxmi, D. Vijayalakshmi and Maruthesha, A. 2018. Application of Polyphenol Extract from Mango Peel Powder as a Source of Natural Phytonutrients into Biscuits. Int.J.Curr.Microbiol.App.Sci. 7(05): 1206-1213. doi: https://doi.org/10.20546/ijcmas.2018.705.147 